\title{
Reflexos sociotemporais da pandemia de Covid-19 no jornalismo: processos de aceleração e desaceleração do Tempo Social
}

\author{
Sociotemporal reflections of Covid-19 Pandemic in journalism: \\ acceleration and deceleration processes of the Social Time \\ Reflexiones sociotemporales de la pandemia Covid-19 en el \\ periodismo: procesos de aceleración y desaceleración \\ del Tiempo Social
}

\section{Laura Storch}

Jornalista, Doutora em Comunicação e Informação (UFRGS). Docente do Programa de Pós-Graduação em Comunicação da Universidade Federal de Santa Maria, coordenadora do Laboratório de Experimentação em Jornalismo (UFSM), membro do Grupo de Pesquisa Estudo de Jornalismo (CNPq/UFSM) e da Rede de Pesquisa Aplicada em Jornalismo e Tecnologias Digitais (SBPJor). Email: laura.storch@ufsm.br

\section{Eduardo Rosa Guedes}

Graduado e Mestre em Ciências Sociais pela Universidade Federal de Santa Maria (UFSM). Doutorando em Sociologia pelo Programa de Pós-Graduação em Sociologia da Universidade Federal de Pelotas (UFPel/PPGS). E-mail: edu.rguedes@gmail.com

\section{Resumo}

A pandemia de Covid-19 modificou de forma abrangente as relações sociais e as percepções sociotemporais, inclusive no campo do Jornalismo. O artigo parte de um debate teórico sobre o Tempo Social para problematizar os reflexos acelerativos e desacelerativos da pandemia nas rotinas e práticas sociais vinculados à produção e circulação de conteúdos jornalísticos. Consideramos a perspectiva teórica sobre aceleração proposta pelo sociólogo alemão Hartmut Rosa, em particular as categorias de aceleração técnica, aceleração dos ritmos de vida e aceleração da mudança social, com vistas a contribuir com a consolidação de leituras sociológicas ampliadas sobre o tempo e as relações sociais.

Palavras-chave: tempo social; aceleração; sociologia; jornalismo; pandemia; Covid-19. 


\section{Introdução}

Em dezembro de 2019 as atenções do mundo começaram a se voltar para os casos de infecção por "sars-cov-2", um vírus da família Coronavírus, no interior da China. O que parecia restrito ao país asiático rapidamente se espalhou por diferentes regiões do mundo, movimento acompanhado globalmente através das narrativas jornalísticas. Em março de 2020 os índices sobre circulação do vírus já permitiam sua classificação como pandemia. A partir daí, as orientações sanitárias sugeriram distanciamento e isolamento social, e as transformações nas rotinas diárias se fizeram sentir de formas muito distintas e alteraram significativamente comportamentos sociais.

Nossa proposta neste artigo é a de refletir sobre os reflexos da pandemia de Covid-19 nos arranjos sociotemporais, com particular atenção para processos de aceleração e desaceleração no contexto do Jornalismo. Partimos da compreensão de que o Jornalismo tem uma relação essencial com a noção "tempo", visto que se caracteriza como atividade comprometida com a narração dos acontecimentos no "presente". Mais do que isso, as lógicas de produção do Jornalismo são fortemente reguladas pelo tempo, e as rotinas noticiosas também colaboram para a construção de uma experiência compartilhada sobre o presente. O contexto da pandemia se apresenta, assim, como um ambiente privilegiado para a observação sobre o tempo em um sentido Sociológico.

De modo a organizar o debate, partimos de uma discussão sobre o Tempo Social, categoria conceitual que busca compreender as relações entre tempo e sociedade como construções sociais heterogêneas, que alimentam e são alimentadas pelas relações que se estabelecem entre diferentes estratos da realidade social. Avançamos para considerações sobre os processos de aceleração do Tempo Social, com especial atenção para o projeto teórico de Hartmut Rosa (2019; 2020), tendo como interesse central os desdobramentos dessa perspectiva nas observações sobre suas implicações no contexto da Comunicação, em particular do Jornalismo. Durante a pandemia, o Jornalismo foi intensamente impactado pelas mudanças do Tempo Social. Processos de aceleração e desaceleração podem ser percebido, de modo concomitante, distendendo práticas jornalísticas altamente rotinizadas, visto que o tempo opera como mediador e como orientador de processos editorais.

\section{O Tempo Social: uma realidade multifacetada}

A dimensão processual da realidade social, aquela em que os fenômenos sociais emergem, tomam forma e influenciam nossas ações, dentre outras coisas, somente é 
compreensível e explicável porque ocorre através do tempo. É somente no tempo, pelo tempo e com o tempo que conseguimos identificar o que mudou, o que permaneceu e os porquês das mudanças, além, é claro, o que podemos (e se podemos) esperar do futuro. Por mais óbvio que isso possa parecer, sobretudo no que tange à formação das nossas referências sociocognitivas das transformações, mudanças e processos inerentes à vida em sociedade, como bem lembraram George Herbert Mead (1932), Alfred Whitehead (1978) e Barbara Adam (1990), o tempo deve ser considerado, simultaneamente, como o único meio e locus privilegiado para tanto, pois ele se refere "[...] ao ritmo ou mudanças envolvidas nos processos sociais” (Gronmo, 1989:342). Em outros termos, o tempo e a dimensão processual da realidade social podem ser vistos como sinônimos.

Do ponto de vista sociológico, a teorização sobre o tempo torna-se ainda mais intrincada, visto que é evidenciado por essa área do conhecimento científico o quão multifacetada tal realidade é, senão, singular ${ }^{1}$. Se o ritmo da vida social está na base da categoria "tempo", conforme Émile Durkheim ([1912] 1996), podemos concordar com a caracterização realizada por Pitirim Sorokin (1970) acerca da singularidade do Tempo Social (ou Tempo Sociocultural). Segundo o autor, ao contrário do Tempo Metafísico, do Tempo Físico-Matemático, do Tempo Biológico e do Tempo Psicológico (às vezes chamado de Temporalidade ${ }^{2}$ ), por exemplo,o Tempo Social difere de ambos, em virtude de as suas propriedades escaparem da mera redução

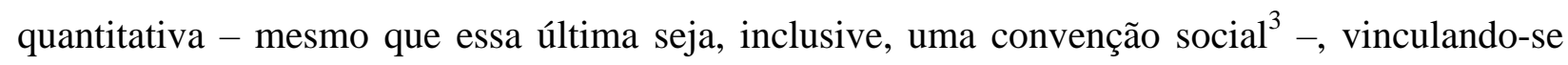
mais à uma dimensão qualitativa. Ainda segundo o autor, o Tempo Social supõe pelo menos sete propriedades sociotemporais que o distingue daqueles outros tempos, quais sejam:

\begin{abstract}
1) supõe e mede fenômenos socioculturais; 2) não ocorre simultaneamente no mesmo grupo e em diferentes sociedade; 3) possui momentos repletos de acontecimentos, momentos críticos ou intervalos, em cuja duração nada aconteceu; 4) não é infinitamente indivisível; 5) é totalmente qualitativo; 6) não é um desenvolvimento vazio, mas sim um tempo produtivo, que, no seu transcorrer, se transforma numa importante agência criadora, modificadora e transformadora de grande número de processos socioculturais; e, por fim, 7) possui um estrutura peculiar - o da aeternitas (movimento circular), o da aevum (era, idade) e o de tempus propriamente praticamente ausente em qualquer outra concepção de tempo (Sorokin, 1970:231-233).
\end{abstract}

Subjacente à citação de Sorokin (1970) reside o fato de que o Tempo Social não possui somente a característica de se apresentar como uma variável epistemologicamente indispensável para compreendermos, e inclusive teorizarmos, as mudanças sociais pelo ponto de vista sociológico, nem que o Tempo Social se define pela sua distinção em relação aos demais tipos de

\footnotetext{
${ }^{1}$ Para um panorama de como o tempo foi caracterizado na Sociologia, notadamente entre as décadas de 1930 e 1970, ver Guedes (2020).

${ }^{2}$ Entendemos por isso, na esteira de André Comte-Sponville (2000), “[...] a unidade - na consciência, por ela, para ela - do passado, do presente e do futuro" (Comte-Spoinville, 2000:31).

${ }^{3}$ Sobre o tempo social e sua dimensão quantitativa/qualitativa, ver também Elias (1998).
} 
tempo. Mais do que isso, o Tempo Social deve ser encarado, seja pela perspectiva sociológica, filosófica ou até jornalística - tão central para o presente artigo -, da mesma forma que Durkheim aludiu sobre o mesmo tema, a saber: o Tempo Social é uma construção social, o que se traduz pela ideia de que ele pode variar de lugar para lugar, (re)alimentado e sendo (re)alimentado por distintas localidades e, eminentemente, articular os diversos "estratos" da realidade social, isto é, encadear os processos sociais de um modo geral.

É mister ressaltar, ainda, que para além de o Tempo Social possuir caraterísticas que o distinguem dos demais tipos de tempo - se é que é possível marcar tão rigidamente uma distinção como fez Sorokin (1970) -, ele também possibilita que tipologicamente sejam identificadas variadas formas de "comportamento". Quem nos mostrou isso, com um certo grau de ambição e audácia teórica, foi Georges Gurvitch na sua obra "The Spectrum of Social Time" ([1958] 1964). Nessa obra, além de Gurvitch (1964:27) definir o Tempo Social como “[...] convergência e divergência dos movimentos dos fenômenos sociais totais, sejam os fenômenos sociais totais globais, grupais ou micro sociais e sejam ou não expressos na estrutura social”, o que evidencia a sua complexidade, heterogeneidade e efemeridade; qualificar a aplicação do seu método Hiper-empirista dialético, isto é, que aplique constantemente uma modulação permanente dos dados da experiência com os conceitos a priori (Gurvtich, [1962] 1987); também foram expostos oito tipos de Tempo Social. Tais tipos de Tempo Social, na perspectiva gurvitchiana, variam conforme a "tomada de consciência" desses mesmos tipos de tempo por parte de diferentes coletividades, quer em nível de apreensão, percepção e simbolização, quer em nível de conceituação e até quantificação. Nas palavras do autor, os oito tipos de Tempo Social são:

(1) Tempo Duradouro [enduring time] - onde o passado é projetado, de maneira contínua, no presente e no futuro; (2) Tempo Enganoso [deceptive time] - onde há uma aparente calma que esconde um grande potencial para crises repentinas; (3) Tempo Irregular [erratic time] - onde há uma cisão entre o passado, presente e futuro ou, mais especificamente, quando surge um novo contexto social; (4) Tempo Cíclico [cyclical time] - onde o tempo está voltado para si mesmo, típico de sociedades arcaicas; (5) Tempo Retardado [retarded time] - típico de comunidades fechadas; (6) Tempo Alternado [alternating time] - onde há uma alternância entre avanço e retrocesso; (7) Tempo de Avanço [time pushing forward] - o valor do futuro é maior do que do presente, por exemplo, o tempo das inovações criativas; (8) Tempo Explosivo [explosive time ] - onde o passado e o presente perdem totalmente o lugar para o futuro, por exemplo, os processos revolucionários (Gurvitch, 1964:13-14).

Todo esse exercício tipológico acerca do Tempo Social realizado por Gurvitch (1964) serviu para o autor salientar o significado que uma exaustiva descrição do Tempo Social, bem como de suas facetas espectrais, logo, múltiplas, contribuem para o desenvolvimento da 
Sociologia, de um modo geral, e para a Teoria Sociológica - principalmente a subárea Sociologia do Conhecimento -, de um modo específico. À vista disso, pelo menos três motivos fundamentais, argumenta Gurvitch, podem ser destacados, quais sejam: (i) cada quadro social e seu ritmo não pode ser analisado sem a variável tempo; (ii) a multiplicidade do tempo é central não somente para a Sociologia, mas também para a "Sociologia do Conhecimento", uma vez que cada quadro social tem sua maneira de perceber, reagir e estruturar-se pelo tempo; (iii) é colocado em cheque a ideia da validade dos determinismos sociais e suas unificações pois, como foi demonstrado, são distintas (Gurvitch, 1964:14).

Com o intuito de evitarmos qualquer dúvida razoável, notadamente aquela em relação a nossa definição de Tempo Social, devemos salientar que temos uma compreensão específica de Tempo Social. Dessa forma, a partir das distintas perspectivas e contribuições sociológicas (Gurvitch, 1964; Gronmo, 1989; Sztompka, 2005), e dado que de modo genérico "[...] não existem dois estados temporalmente distintos de uma entidade social que possam ser idênticos" (SztompkA, 2005:90), devemos salientar que compreendemos por Tempo Social: uma totalidade heterogênea que articula temporalidades distintas e é percebida de modos distintos por indivíduos, grupos e sociedades, em virtude de possuir qualidades, ritmos e durações variadas nas diferentes camadas da realidade social ${ }^{4}$. Somente com essa compreensão e definição de Tempo Social, cremos, conseguiremos expor com maior clareza e facilidade dois comportamentos do Tempo Social que fundamentam o presente artigo e a característica da Sociedade Contemporânea, no sentido de uma ontologia do presente, assim como a sua apreensão teórico-conceitual, a saber: aceleração e desaceleração do tempo social. Esses dois últimos, e isso é importante ressaltar, comportam-se tão paradoxalmente, inclusive, na atual pandemia de Covid-19 como iremos mostrar sob a ótica da comunicação, singularmente, pela ótica do jornalismo mais adiante. Antes de avançarmos, entretanto, faz-se necessário aprofundar a perspectiva sobre o Tempo Social para a compreensão de algumas particularidades das dinâmicas temporais no Jornalismo.

\section{Jornalismo e Tempo Social: a institucionalização de uma experiência social do presente}

O tempo é uma variável fundamental para o Jornalismo, articuladora de seus modos de produção e das relações sociais que promove e que a constituem. O Jornalismo narra os

\footnotetext{
${ }^{4}$ Essa compreensão/definição de Tempo Social foi previamente formulada na tese de doutorado, ainda em andamento, do segundo autor do presente artigo.
} 
acontecimentos que agencia à categoria notícia ${ }^{5}$ a partir de uma relação complexa com o Tempo Presente, criado e recriado a partir de técnicas de narração e de rotinas produtivas particulares. A noção de Tempo Presente pode ser compreendida como "um fenômeno social composto por práticas sociais, relações de sentido e atributos inscritos em produtos culturais" (Franciscato, 2005:15) que tornam sua experiência concreta, ou seja, "compreensível como um objeto social e dotado de um conteúdo com um sentido intersubjetivamente partilhado" (Franciscato, 2005:16).

A temporalidade pode, até mesmo, ser observada como orientadora de algumas das finalidades do Jornalismo, em um sentido normativo da profissão/instituição. Segundo Reginato (2018:15 [Grifos nossos]), o jornalismo tem 12 finalidades a cumprir:

a) informar de modo qualificado; b) investigar; c) verificar a veracidade das informações; d) interpretar e analisar a realidade; e) fazer a mediação entre os fatos e o leitor; f) selecionar o que é relevante; $g$ ) registrar a história e construir memória; h) ajudar a entender o mundo contemporâneo; i) integrar e mobilizar as pessoas; j) defender o cidadão; k) fiscalizar o poder e fortalecer a democracia; 1) esclarecer o cidadão e apresentar a pluralidade da sociedade.

A construção diária das notícias tem como ponto fundamental o reconhecimento de acontecimentos vinculados à noção de presente. Mas o conjunto dessas histórias oferece ao leitor mais do que uma perspectiva do "agora": vistos no "futuro" são relatos sobre o "passado", documentos da memória social (Chauveau; Tétart, 1999; Laccouture, 2001; Bédarida, 2002; Le Goff, 2012; Monteiro, 2018). A construção da memória pelo Jornalismo é operada a partir de narrativas acumuladas que tem como orientação a "presentificação" dos acontecimentos, efeito realizado por meio da linguagem. Como nos lembra novamente Franciscato (2005), o presente do Jornalismo não é, necessariamente, o presente do acontecimento, mas também o presente da revelação pública do acontecimento. Tornar conhecido é também uma forma de presentificar o acontecimento. Como explica Dalmonte (2010:339):

\begin{abstract}
Se o tempo do jornalismo é o presente, o agora, que coloca ocorrido e leitor num mesmo cenário, é inegável que, a todo o momento, este presente presentifica fatos passados, determinantes para a fundamentação daquilo que se apresenta como surgindo no instante atual. Quando considerada a perspectiva contratual da comunicação, na qual se valoriza "aquilo que surge agora", pode-se, por equívoco reducionista, interpretar tal constatação como a preponderância do atualismo. No entanto, o discurso, ao lançar suas bases no passado, confere profundidade aos fatos, o que dá densidade ao presente. Da mesma forma, o presente densificado pela perspectiva histórica prolonga-se sobre o futuro, conferindo ao atual também a dimensão futura, fazendo que, por meio do fato apresentado, o leitor transite do passado ao futuro, tornado próximo à medida que as expectativas dizem respeito a projeções estabelecidas a partir do agora.
\end{abstract}

Franciscato (2005) situa um dos movimentos temporais operados pelo e através do Jornalismo na compreensão do Jornalismo enquanto prática social. Ao produzir conteúdo

\footnotetext{
${ }^{5}$ A definição sobre acontecimentos jornalísticos é amplamente estudada no contexto das pesquisas em jornalismo, com particular relevância para o debate sobre "critérios de noticiabilidade". Ver Silva, Silva e Fernandes (2014).
} 
noticiosos a partir de uma lógica de atualidade, o Jornalismo colabora para reforçar formas de a sociedade vivenciar uma experiência coletiva do tempo presente. Esse processo permite a consolidação de um sentido de simultaneidade que é elaborado socialmente mesmo que o indivíduo esteja fora do alcance da experiência direta dos acontecimentos narrados. A produção institucional de conteúdos de atualidade "oferece à sociedade formas específicas pelas quais indivíduo e sociedade produzem a sua vivência social do momento presente, tornando-se, muitas vezes, uma das condições necessárias para essa vivência se realização em alguns tipos de relações sociais" (Franciscato, 2005:21). O Jornalismo, dessa forma, opera outro movimento temporal socialmente relevante, visto que colabora como suporte de experiência social do presente. "Os eventos jornalísticos não são apenas marcadores simbólicos sobre o tempo presente, mas são definições temporais sobre modos de viver o presente" (Franciscato, 2005:21), mais do que isso, "o primeiro saber que o jornalismo estabelece é a definição de contemporâneo. É o jornalismo quem diz “"isto é atual', 'você precisa saber disto porque, isto é da sua época', 'você só estará conectado a sua época se obtiver esta informação que estou trazendo"” (Benetti, 2013:46).

Um terceiro movimento temporal é relevante para compreendermos as implicações multifacetadas do Tempo Social no contexto do Jornalismo: é aquele que Franciscato (2005) denomina como "temporalidades institucionalizadas do Jornalismo". Mais do que colaborar para a construção de um sentido de simultaneidade social e operar como suporte de experiência do presente, o Jornalismo também vivencia uma organização temporal interna, relativa às suas práticas e com consequente reflexo na definição de seu produto. "O tempo se institucionaliza tanto como fator de identidade como de tensão" (Franciscato, 2005:18) e, mais do que isso, a temporalidade dos processos de produção delimita a forma cultural do principal produto jornalístico: "A notícia traz, normalmente de forma explícita, marcas do presente que afirmam sua singularidade temporal, sua duração breve na expressão de um presente que se esvai" (Franciscato, 2005:18). O trabalho jornalístico é marcado e cronometrado por essa existência efêmera das notícias, de modo que a organização jornalística aplica mecanismos regulares de controle da volatilidade das informações noticiosas. Esses mecanismos podem se dar pela substituição regular das informações ou por processos continuados de atualização das informações referentes a um conteúdo particular. Tal procedimento tem como objetivo o planejamento das atividades de trabalho e a estrutura de rotinas produtivas, de funções 
profissionais e de uma agenda de circulação dos produtos - a periodicidade ${ }^{6}$. O tempo de produção determina modalidades de enunciação dos acontecimentos e pode orientar a substituição ou a atualização de um acontecimento na ordem diária de publicação das notícias.

Estas considerações conceituais sobre as temporalidades do e no Jornalismo buscam apontar para alguns condicionantes particulares deste campo social e serão relevantes para a discussão mais profunda sobre os atravessamentos temporais da pandemia de Covid-19 na produção e circulação de notícias. O Jornalismo também precisa ser compreendido a partir de sua interação mais ampla com os desenvolvimentos sociais contemporâneos. Os processos de aceleração e desaceleração, aos quais aludimos anteriormente, se farão sentir nas práticas sociais atravessadas pelo Jornalismo. Nesse sentido, avançamos para a compreensão desses fenômenos de forma particular.

\section{Efeitos sociotemporais no presente: aceleração e desaceleração do Tempo Social durante a pandemia de COVID-19}

Embora seja algo que recentemente tenha sido teorizado de modo explícito no âmbito teórico da Sociologia, mais ou menos a partir da década de 1970, a aceleração do Tempo Social não é de modo algum uma novidade na realidade social, principalmente na Europa Ocidental. A própria Sociologia, como disciplina do saber científico, nasce com e por causa das aceleradas transformações sociais, muitas delas "filhas legítimas" do desenvolvimento da Ciência Moderna e, por óbvio, dos efeitos da industrialização em boa parte da Europa, algo explicitamente refletido na Teoria do Conhecimento Social de Auguste Comte (1983) e no diagnóstico de Émile Durkheim (2010) sobre a Divisão do Trabalho Social. Assim, graças a característica multifacetada do Tempo Social, apresentada na primeira seção, podemos afirmar, juntamente com Reinhardt Koselleck (2006), que esse efeito sociotemporal emergiu após o gradual processo de secularização que se instalou na Europa a partir do século XVI.

Depois daquele período, grosso modo, a razão moderna foi eliminando gradualmente os "finalismos transcendentais" propagados pelo pensamento religioso em geral. Uma forte orientação social de racionalização da vida - termo largamente usado por Max Weber (2004, [1917] $2015^{7}$ ), especialmente quando fazia referência ao protestantismo ascético -, começou a determinar o mundo e o modo de o ser humano ser-no-mundo (perspectiva imanente) e, por efeito, desarticular o sentido e a razão de ser do espaço de experiência (presente) com o

\footnotetext{
${ }^{6}$ Segundo Franciscato (2005:137-138), “a noção de periodicidade implica em percebermos um aspecto específico que será fundamental ao jornalismo: o surgimento de uma necessidade social de que a sociedade fosse abastecida por notícias em períodos regulares e com intervalos mais curtos".

${ }^{7}$ Ver também Sell (2013).
} 
horizonte de expectativa (futuro), antes tão logicamente fundamentos pelo caráter escatológico da cultura judaico-cristã. Se antes, durante a força escatológica da cultura judaico-cristã, a ruptura com o passado somente seria experienciada pela humanidade no momento do Juízo Final, após o século XVI, o Prognóstico Racional e a Filosofia da História demonstraram com muita propriedade, significativamente a partir do século XVIII, um novo futuro, um futuro radical, inédito e acelerado. Ambas as perspectivas concretizaram uma ousada combinação entre política e profecia, o que seria fundamental para o Pensamento Moderno e sua forma de conceber o Tempo Social, a saber: a ideia de progresso. A ideia de progresso, então,

[...] descortina um futuro capaz de ultrapassar o espaço do tempo e da experiência tradicional, natural e prognosticável, o qual, por força de sua dinâmica provoca por sua vez novos prognósticos, transnaturais e de longo prazo. O futuro, a partir desse conceito de progresso, é caracterizado então por dois momentos: pela aceleração e por seu caráter desconhecido (Koselleck, 2006:36).

Nesse prisma, ainda conforme Koselleck (2006), o progresso científico e técnicoindustrial, mais especificamente, a retroalimentação ou a simbiose entre o desenvolvimento científico e tecnológico - considerada por muitos pensadores, tais como Paul Virilio (1999), Hermínio Martins (2011) e Marcos Lacerda (2020), dentre outros, como "Tecnociências", emergentes após a década de 1970, juntamente com as Tecnologias de Informação e Comunicação (TICs) - foi um elemento-chave para que a experiência da aceleração do Tempo Social fosse catalisada em boa parte da Europa Ocidental e nos Estados Unidos. Por meio dessa simbiose entre ciência e tecnologia, então, o progresso humano poderia ser alcançado mais rapidamente. Por isso, não é à toa que Koselleck (2006) afirma que o olhar do espaço de experiência, ao longo do século XVIII até os dias de hoje, cada vez mais vislumbravam um futuro longínquo, mas que poderia, sob certas condições, ser dominado. Novamente segundo o autor:

Passou a ser uma tese universal da experiência das inovações científicas e de sua aplicação industrial que elas permitem esperar novos progressos, que não podem ser previstos de antemão. O futuro, mesmo não podendo ser deduzido da experiência, trouxe não obstante a certeza de que as invenções e descobertas científicas iriam criar um mundo. Ciência e técnica estabilizaram o progresso como sendo a diferença temporal progressiva entre a experiência e a expectativa. Por último, existe um indicador infalível de que esta diferença só se conserva quando se modifica continuamente: é a aceleração. Tanto o progresso sociopolítico quanto o progresso técnico-científico modificam os ritmos e os prazos do mundo-da-vida graças à aceleração. Ao contrário do tempo da natureza, o progresso adquire uma qualidade genuinamente histórica (Koselleck, 2006:321).

Baseado nas considerações de Koselleck (2006), dentre outros autores como Paul Virilio (1993), Hermann Lübbe ([1998] 2009) e Georg Simmel (1998, 2005), o sociólogo Hartmut Rosa talvez seja um dos autores que mais vem se dedicando à uma sistematização e à uma 
reconceitualização da Teoria Social atual com base no processo de aceleração social da Modernidade $\operatorname{Tardia}^{8}$, não obstante tenha deixado claro que não pretende criar uma "Sociologia do Tempo". Hartmut Rosa, no seu livro "Aceleração: a transformação das estruturas temporais da Modernidade" ([2005] 2019), propõe demonstrar que a teorização do processo de aceleração social possibilita uma análise que evidencia as mudanças na relação entre o indivíduo, a estrutura social e o sistema cultural. Mais do que isso, Rosa (2019) busca compreender, explicar e sistematizar um paradoxo presente na Modernidade Tardia, a saber: não dispomos de tempo, embora o ganhemos em abundância. Com isso, o autor quer salientar a "aura" que paira sobre nós atualmente, ou seja, temos uma ânsia por realizar mais tarefas em menos tempo e experimentar o maior número possível de opções disponíveis na vida graças à rapidez das Tecnologias de Informação e Comunicação (TICs), dentre outras facilidades tecnológicas e estilos de vida.

Todavia, Rosa (2019) parte do pressuposto de que a aceleração social não é linear, mas ocorre em "saltos" [schubweise], visto que "[...] sempre encontra obstáculos, resistências e contra movimentos que podem retardá-lo, interrompê-lo e, por vezes, até inverter seu sentido" (Rosa, 2019:83). Existe, portanto, uma constante tensão entre o processo de aceleração social (movimento) com elementos inerentes a ele (inércia), entre forças ativas e forças reativas. Somente com a elucidação dessa tensão é que se pode teorizar sobre uma aceleração da sociedade tardo moderna e, "de antemão, que o processo de aceleração social não ocorre linearmente, mas no bojo de saltos qualitativos, intimamente relacionados ao emprego de novas tecnologias" (Tziminadis, 2018:18).

Para tanto, Rosa (2019) direciona o seu olhar para a retroalimentação, e os efeitos, causados pela aceleração técnica, a aceleração da mudança social e a aceleração do ritmo da vida. Porém, longe de determinar a primazia de qualquer uma dessas modalidades de aceleração, o autor busca salientar que elas desencadeiam uma lógica processual que foi claramente explicada por Diego Viana (2018): a aceleração da mudança social implica uma aceleração dos ritmos, que só pode se realizar graças à aceleração técnica, que por sua vez produz mudanças sociais, e assim por diante. A Modernidade Tardia, nesse prisma, somente consegue manter seu nível de funcionamento através do seu próprio movimento quando mantém o funcionamento das suas estruturas pela expansão da sua tríade imperativa: crescimento, aceleração e adensamento de inovações. Isso significa "que o mundo como um todo, em sua materialidade, é posto sob pressão para dinamizar-se: pessoas, dinheiro, bens e matérias primas são postos em movimento"

\footnotetext{
${ }^{8}$ Além de Hartmut Rosa, é claro, Carmen Leccardi (2014) e Judy Wajcman (2017) também se destacam no âmbito teórico internacional da Sociologia.
} 
(Rosa, 2017:372). A análise realizada por Rosa acerca dessa relação de retroalimentação ${ }^{9}$ será explorada adiante, pois, neste momento é relevante salientar que o autor fez uso dessa perspectiva teórica para lançar mão de alguns insights sobre a pandemia de Covid-19.

No texto "La sociedad ante la desaceleración forzada: una interpretación sociológica de la crisis del coronavirus" (2020), Rosa defende a tese de que enfrentamos, por causa da pandemia de Covid-19, um processo de desaceleração forçada sem precedentes. Especificamente, “[...] estamos diante de uma tremenda reviravolta e desestabilização estrutural do sistema social globalmente dominante" (Rosa, 2020:21), sobretudo da dimensão material da realidade social. Essa última, como é sabido, é caracterizada por um modo de estabilização dinâmica, mas que, em virtude desse momento extraordinário, como a guerra, de repente freou bruscamente. Claro que o seu inverso, a realidade digital-social, não foi atingida, mas ainda mais acelerada como é possível observamos na circulação, comunicação e produção de informações.

Na realidade digital-social, mais do que nunca a ideia de Inércia Polar formulada por Paul Virilio (1993), fundamental para a Teoria da Aceleração Social de Hartmut Rosa, é explicitada: o meio digital, como a Internet e a Televisão, faz com que o "aqui" e o "lá" sejam substituídos pelo "agora", fazendo com que o homem esteja desapropriado do tempo, do espaço, do seu corpo e das relações sociais. A inércia diz respeito, portanto, a "[...] esse veículo audiovisual, veículo estático, substituto das nossas deslocações físicas [espaciais] e prolongamento da inércia domiciliária que acarretaria enfim o trinfo da sedentariedade, de uma sedentariedade agora definitiva" (Virilio, 1993:35 ${ }^{10}$ ).

Apesar de estar dirigindo seus insights sobre a pandemia sobretudo ao contexto europeu, Rosa (2020) aponta que essa desaceleração forçada [Zwangsentschleunigung], da mesma forma que o Tempo Social - como salientamos anteriormente -, se constitui numa construção social, visto que no seu âmago não encontramos simplesmente o poder do vírus Sars-Cov-2, mas o efeito imediato das decisões políticas dos governos. Tais decisões políticas dos governos, ressalta Rosa, ao contrário do que muitas teorias "militantes" deterministas afirmavam, não está protegendo mais o mercado mundial. Na realidade, e metaforicamente falando, é como se as decisões políticas tivessem colocado o pé em uma das engrenagens, nos mecanismos propulsores, criticando toda a lógica irrefreada de crescimento e aceleração social. De modo mais enfático, Rosa afirma que:

[...] esta ruptura abrupta nas rotinas de ação e nos processos da modernidade, que modifica profundamente as práticas cotidianas e as lógicas habituais de ação e interação em vários âmbitos da sociedade, foi e é o resultado da ação política deliberada e planejada (Rosa, 2020:22).

\footnotetext{
${ }^{9}$ Para uma síntese da Teoria da Aceleração Social formulada por Hartmut Rosa, ver Guedes e Storch (2020).

${ }^{10}$ Ver também Guedes (2021).
} 
Além disso, Rosa (2020) também ressalta que as decisões políticas, materializadas pelo Estado, parecem ter colocado em xeque a ideia de que a Sociedade Contemporânea, sob o ponto de vista sistêmico - uma leitura um tanto contraditória de Rosa -, não teria mais um centro unificador, justamente por ser policontextual, como bem argumentaram Niklas Luhmann (2006; 2016). Agora, por motivo de força maior (Covid-19), parece, segundo Rosa, que o Estado ${ }^{11}$ tomou o centro da realidade social, posto que "de um dia para o outro, o Estado passa a ser o ator central e subordina todos os pontos de vista sob um único objetivo: o combate ao vírus" (Rosa, 2020:23). Com base nessa assertiva e frente à atuação do Estado em relação à pandemia, Rosa (2020) reconhece que ainda visualizamos (se visualizamos) um horizonte ofuscado, mas que possibilita uma série de questionamentos - para não dizer expectativas.

Os questionamentos trazidos à baila por Rosa (2020), sob a forma de paradoxos, dizem respeito aos possíveis cenários pós-pandemia, ou melhor, pós-desaceleração forçada, quais sejam: estamos diante de um processo revolucionário no modo de estabilização dinâmica da Sociedade Contemporânea? Ou, ao contrário, a desaceleração forçada - no sentido metafórico de uma pedra que atrapalha a dinâmica das engrenagens, mas que está sendo pressionada pelas mesmas, e quando é retirada faz com que essas mesmas engrenagens se acelerem bruscamente permitirá a restituição dos imperativos do modo de estabilização dinâmica? Pois bem, um dos possíveis cenários é a retomada crítica de certos problemas sociais, como a questão ambiental, dentre outras, ou, inclusive, uma forte reformulação no âmbito teórico da Sociologia, pois essa última, na perspectiva de Rosa, deve aprender e se importar mais com esses momentos excepcionais, no intuito de um maior engajamento - engajamento que deve estar orientado cientificamente, se é que isso é possível.

Ao fim e ao cabo, o que importa nesses incipientes "insights" lançados por Rosa (como ele mesmo reconhece) reside no seguinte aspecto:

Em relação à crise do coronavírus, isto significa que deve ser utilizado tudo o que, à luz dos conhecimentos sociológicos disponíveis, possa ajudar a compreender teoricamente a situação de crise e a sua dinâmica e desdobramentos. As propostas interpretativas assim geradas estão sempre abertas à revisão e têm necessariamente um caráter ad hoc: amanhã um novo fenômeno, acontecimento ou achado pode fazer com que a interpretação atual pareça desatualizada ou falsa. Como disse, essas propostas interpretativas são entendidas não como saberes sacrossantos, mas como o que realmente são: interpretações que são submetidas a constantes críticas no discurso público, justamente aspirando a serem modificadas e "aprimoradas" por meio de objeções e críticas. Dessa forma, as análises sociológicas contribuem (nas sociedades modernas) para aqueles "relatos" que acabam se tornando autointerpretações influentes e socialmente operantes, e coagulando em (novas) instituições. Os sociólogos têm uma vantagem sobre outros grupos populacionais - por exemplo, políticos e jornalistas -: a sociedade disponibiliza os recursos necessários para o cumprimento dessa tarefa.

\footnotetext{
${ }^{11}$ Ver também Gros e Torres (2020).
} 
Seria interessante por ora, assim, a Sociologia, em geral, e os sociólogos, em específico, ficarem atentos a presente desaceleração forçada. Mesmo que ambos residam na simples dimensão de conjecturas, dado a imprevisibilidade do cenário atual, faz-se necessário "abrir mais olhos", estar atento ao desenrolar das decisões políticas, muito no sentido do artigo escrito pelos autores Léo Peixoto Rodrigues, Marcos Lacerda e Everton Garcia no presente volume. Somente dessa maneira séria, “[...] a Sociologia pode contribuir e fomentar a liberação e aplicação criativa de recursos sociais criativos para uma mudança do paradigma [estabilização dinâmica]" (Rosa, 2020:30), e, acima de tudo, estar preparado (na medida do possível) para o nos espera.

\section{Confluências e disjunções temporais no Jornalismo em tempos de Pandemia}

Partimos das provocações de Hartmut Rosa e das discussões sobre o Tempo Social e avançamos na observação de um fenômeno particular, o Jornalismo no contexto pandêmico de Covid-19. Como salientamos, o Jornalismo é uma instituição da Modernidade que possui relação essencial com a noção de tempo, contribuindo para a configuração social de uma ideia de Tempo Presente socialmente compartilhado. Mas as dinâmicas temporais no Jornalismo também são múltiplas e interrelacionadas com conformações mais amplas do Tempo Social, compreendido neste trabalho como uma totalidade heterogênea que articula temporalidades distintas e é percebida de modos distintos por indivíduos, grupos e sociedades, em virtude de possuir qualidades, ritmos e durações variadas nas diferentes camadas da realidade social.

A emergência da pandemia de Covid-19 modificou drasticamente muitas das lógicas funcionais do Jornalismo. A diminuição dos fluxos sociais diários, em particular urbanos, afetaram a rotina dos profissionais e dos leitores ${ }^{12}$. Restrições de mobilidade e presencialidade, ampliação do trabalho remoto, demandas de cuidados em saúde para si ou para familiares, restrições de acesso a escolas e ambientes de entretenimento, entre tantas outras mudanças sentidas no cotidiano de muitas pessoas ao redor do mundo, também impactaram os profissionais e o trabalho da Comunicação. O Jornalismo foi considerado atividade essencial desde os primeiros dias após a declaração da Organização Mundial da Saúde (OMS) sobre a situação de pandemia, em 11 de março de 2020. No Brasil, o decreto $10.288^{13}$, de 22 de março de 2020, determinava "resguardar o exercício pleno e o funcionamento das atividades e dos serviços

\footnotetext{
${ }^{12} \mathrm{O}$ termo leitor é tomado aqui como representativo da figura que, no contrato de Comunicação elaborado por Charaudeau (2007) é representado pelo polo "para quem se diz". No contexto do jornalismo, essa figura pode ser denominada também como ouvinte, espectador, audiência, público, assinante, entre outras denominações. Para um aprofundamento do debate, ver Storch (2012).

Disponível em https://www.in.gov.br/en/web/dou/-/decreto-n-10.288-de-22-de-marco-de-2020-249098577. Acesso em 14 ago. 2021.
} 
relacionados à imprensa, considerados essenciais no fornecimento de informações à população". A desaceleração forçada [Zwangsentschleunigung] sugerida por Rosa (2020) foi vivenciada de modos muito distintos pelo campo profissional da Comunicação e pelo Jornalismo, que passaram a ser demandados de forma ampliada, muitas vezes em detrimento das condições concretas de produção de conteúdos e notícias.

Exploramos (algumas) confluências e disjunções temporais no Jornalismo durante a pandemia de Covid-19 como forma de contribuir com a investigação sociológica sobre o Tempo Social, visto que este se apresenta como um locus potente de observação de processos de aceleração e desaceleração social. Nos valemos, como forma de organização analítica, das categorias de aceleração propostas por Rosa (2019), quer sejam, aceleração técnica, aceleração da mudança social e aceleração dos ritmos de vida.

Talvez uma das formas mais evidentes de observação dos processos de aceleração social se dê a partir do que Rosa chama de "aceleração técnica", um processo intencional promovido pelos desenvolvimentos tecnológicos "direcionados a um objetivo" (Rosa, 2019:141). A velocidade sempre crescente dos transportes e o desenvolvimento da capacidade de resposta das TICs favoreceram a contração do espaço e a consolidação do tempo como matriz de orientação da vida social. No contexto da pandemia, a desaceleração forçada [Zwangsentschleunigung] sustentada por Rosa (2020) pode ser compreendida como resultado de um fenômeno de inércia acelerativa decorrente de um limitador natural ${ }^{14}$ (a Covid-19). Entretanto, este fenômeno foi acompanhado pelo aumento significativo do volume de dados digitais transmitidos pela Internet, um processo de virtualização das relações sem precedentes. Apenas para citar um exemplo, o Brasil Internet Exchange, um dos maiores conjuntos de Pontos de Troca de Tráfego de Internet (PTT) do mundo, bateu recorde histórico ao atingir o pico de troca de tráfego de $16 \mathrm{Tbit} / \mathrm{s}$ (Terabits por segundo), no dia 07 de março de $2021^{15}$. Este volume de dados é $60 \%$ maior que o registrado em março de 2020. De outro lado, a pandemia também apontou para fenômenos de desaceleração, como podemos reconhecer na extrema desigualdade de acesso às TICs no país: não apenas as desigualdades econômicas, mas também a escassez de distribuição da estrutura física de conexão, em particular no campo, colocou em evidência que a Internet não é uma realidade para parte importante dos brasileiros.

\footnotetext{
${ }^{14}$ A categoria de inércia denominada por Rosa (2019) como "limites de velocidades naturais" pode ser definida a partir da observação de "freios" naturais e/ou antropológicos que limitam a capacidade ambiental de processamento das ações humanas (poluentes e rejeitos), mas também dos limites físicos e cognitivos das pessoas (marcadamente a partir do adoecimento mental, como depressão e a síndrome de Burnout). Ver Guedes e Storch (2020).

15 Disponível em https://ix.br/noticia/releases/ix-br-bate-recorde-historico-ao-atingir-16-tbit-s-de-pico-de-trafegointernet/. Acesso em 14 ago. 2021.
} 
No contexto da Comunicação, essa aceleração técnica também pode ser reconhecida no aumento da demanda por conteúdo online. Segundo dados da agência Kantar Ibope Media, "em 2020, cada pessoa passou cerca de 37 minutos a mais com a TV ligada por dia do que em 2019, totalizando $07 \mathrm{~h} 09 \mathrm{~m}$ diários" ${ }^{\prime 16}$. Entre os dados mais relevantes da pesquisa, que tem como foco o Brasil, está o consumo de vídeo online, que atingiu a marca de $84 \%$ de crescimento nos últimos três anos. Durante a pandemia, a demanda por conteúdos jornalísticos também foi acelerada, revertendo uma série histórica de dados desfavoráveis ao Jornalismo comercial (Newman et al., 2021), que vinha acompanhando a fragmentação de seus níveis de audiência entre diferentes ambientes de comunicação, em particular na Internet (redes sociais, podcasts, VoDs ${ }^{17}$, entre outros). Mais do que a diminuição dos níveis de audiência, existia uma percepção crescente entre os publishers do setor de notícias acerca dos questionamentos da audiência sobre o papel social do Jornalismo e sobre a confiança nas notícias. Segundo o relatório Reuters Institute Digital News Report 2021,

\begin{abstract}
A confiança nas notícias cresceu, em média, seis pontos percentuais na sequência da pandemia de Coronavirus com $44 \%$ da nossa amostra total afirmando que confiam na maioria das notícias a maior parte das vezes. Isto inverte, em certa medida, as recentes quedas na confiança média, trazendo estes níveis de volta aos de 2018. A Finlândia continua a ser o país com os níveis mais elevados de confiança global (65\%), e os EUA têm agora os níveis mais baixos (29\%) na nossa pesquisa. (Newman et al., 2021:9 [Tradução nossa]).
\end{abstract}

No caso brasileiro, o consumo de notícias pela televisão teve um expressivo aumento em 2020, quando os dados de audiência são comparados com o ano de 2019: o tempo médio diário de assistência subiu 30\%, enquanto o total de audiência individual de noticiários aumentou $58 \%{ }^{18}$.

A atendimento a essa demanda é possível em um contexto pandêmico apenas por conta da acelerada digitalização dos processos comunicacionais das últimas décadas. Mas isso não significa que a operacionalização (ao menos inicialmente) improvisada de um "noticiário home office" tenha se dado sem contratempos. Uma importante pesquisa, realizada no Brasil pelo Centro de Pesquisa Comunicação e Trabalho, vinculado à Escola de Comunicação e Artes da USP, mostrou que grande parte das empresas de comunicação não estavam preparadas para uma mudança radical em seu modelo de produção.

Na transferência para o espaço doméstico [em 2020], os equipamentos e as ferramentas de trabalho ficaram às custas dos próprios profissionais, foram poucas as empresas que supriram as necessidades mínimas para a continuidade do trabalho, fornecendo

\footnotetext{
${ }^{16}$ Disponível em https://www.kantaribopemedia.com/estudos-type/inside-video/. Acesso em 10 ago. 2021.

17 Acrônimo para a expressão em inglês "Vídeo on Demand", a modalidade VoD é representada por serviços de streaming de conteúdos audiovisuais, como Netflix, Prime Vídeo, Disney Plus, Hbo Go, entre outro.

${ }^{18}$ Disponível em https://www.kantaribopemedia.com/estudos-type/inside-video/. Acesso em 10 ago. 2021.
} 
infraestrutura básica: computador, câmera, microfones, softwares, sistemas de gestão, mobiliário, conta de internet, celular entre outros equipamentos necessários (Figaro, 2021:13).

Para além dos equipamentos, a pesquisa ainda relata a necessidade de construção de novas rotinas de trabalho, em particular com o apoio de plataformas online de gerenciamento de projetos (Figaro, 2021). Mais do que isso, as mudanças nos hábitos e necessidades da audiência se somaram aos rearranjos das lógicas de trabalho, exigindo das empresas adequações de suas estratégias de produção. Dois exemplos relevantes: no período inicial das restrições de circulação impostas em diferentes lugares do planeta, jornais impressos passaram a não entregar as edições diárias aos assinantes. Isso aconteceu porque o processo de "fechamento de edições" das redações de jornais impressos é orientado pelo trabalho presencial, mas também, e significativamente, porque os leitores passaram a apresentar restrições (e mesmo se recusaram) a receber os volumes em suas casas (Newman et al, 2021). No caso da televisão, houve ajustes nas grades de programação, com aumento do espaço destinado aos gêneros Jornalismo, Reality Shows, Filmes e Novelas. Programas de auditório, transmissões de shows musicais e a programação esportiva semanal deixaram de ocupar os espaços - muitos deles nobres - nas grades e foram substituídos por reprises e pelo aumento da programação noticiosa. No caso específico do Jornalismo, entre abril de 2019 e abril de 2020, o gênero jornalístico aumentou $41 \%$ sua participação nas grades televisavas brasileiras ${ }^{19}$.

$\mathrm{O}$ volume de dados sobre a pandemia, que passou a ser disponibilizado e demandava o processamento jornalístico, também merece destaque. Em um período de apenas cinco meses, no começo de 2020, e apenas em um repositório científico, o PubMed, existiam 19.251 artigos indexados pelo tópico "COVID” (Venkataramanan; Chatterjee, 2020). Atualmente o mesmo repositório aponta um total de 102.760 artigos indexados pelo tópico "sars-cov-2"20. A quantidade de trabalhos submetidos, muitos deles em modalidade de pré-print e sem avaliação por pares, dificultou o trabalho de seleção de informações por parte dos jornalistas, mesmo para o conjunto mais reduzido de jornalistas especializados em ciência ou medicina. A variedade de subtemas, como taxas de infecção e mortalidade, estratégias de controle da propagação do vírus, busca por tratamentos, surgimento de variantes, entre outros, exigiam dos profissionais um cuidado redobrado com as apurações e a necessidade de acesso recorrente a especialistas, em particular epidemiologistas. No contexto do Jornalismo de Dados, os maiores desafios se deram na sistematização de dados confiáveis sobre registros de casos de infecção e óbitos. Em particular no Brasil (Roncalli; Lacerda, 2020), a insegurança dos jornalistas acerca dos dados

\footnotetext{
${ }^{19}$ Disponível em https://www.kantaribopemedia.com/estudos-type/inside-video/. Acesso em 10 ago. 2021.

${ }^{20}$ Busca realizada no site PubMed https://pubmed.ncbi.nlm.nih.gov/. Acesso em 10 ago. 2021.
} 
fornecidos pelo Ministério da Saúde, e a ausência de protocolos precisos para a coleta de informações fez com veículos de imprensa passassem a produzir os dados por conta própria talvez um dos exemplos mais emblemáticos seja o que foi chamado de Consórcio de Imprensa: "Em resposta à decisão do governo Jair Bolsonaro de restringir o acesso a dados sobre a pandemia de Covid-19, os veículos G1, O Globo, Extra, O Estado de S.Paulo, Folha de S.Paulo e UOL decidiram formar uma parceria e trabalhar de forma colaborativa para buscar as informações necessárias nos 26 estados e no Distrito Federal”, explicou o site de notícias G121.

A limitação dos deslocamentos físicos restringiu o acesso às fontes, em particular quando relacionado à necessidade de confirmação de informações, não apenas sobre a pandemia, nos processos de apuração. Muitas pautas foram apuradas à distância ou até deixaram de ser produzidas, entre tantos motivos por conta deste afastamento da rotina presencial, mas também porque diferentes acontecimentos que integravam a rotina dos noticiários foram paralisados (parcial ou totalmente) durante períodos significativos. Um exemplo relevante é o da cobertura esportiva que, em particular em 2020, foi fortemente impactada pela proibição da realização de eventos rotineiros, como campeonatos e competições. O estudo realizado por Sean Sadri et al. (2021: 01) mostrou uma mudança consistente no enquadramento da cobertura produzida pelos jornalistas esportivos norte-americanos: “À medida que a pandemia se foi generalizando, a saúde e a segurança tornaram-se foco predominante dos veículos esportivos nacionais".

Processos de aceleração e desaceleração vão se sobrepondo na rotina jornalística durante a pandemia, mas o resultado geral na qualidade de vida dos profissionais parece ser negativo. Certamente, nos próximos anos muitos estudos nos permitirão reconhecer particularidades destas situações. Mas alguns dados preliminares já suportam a ideia de que a aceleração técnica até aqui apontada serviu como engrenagem para uma aceleração importante do ritmo de vida dos profissionais. Na perspectiva de Rosa (2016:31), a aceleração do ritmo da vida diz respeito ao “[...] aumento do número de episódios de ação ou experiência por unidade de tempo; quer dizer, é a consequência do desejo ou necessidade sentida de fazer mais coisas em menos tempo". Para problematizar essa questão fazemos referência, mais uma vez, ao trabalho de Roseli Fígaro (2021), que mapeou as condições de trabalho dos comunicadores durante a pandemia de Covid19. Em particular o home office, que representa a modalidade de trabalho de $68 \%$ dos

\footnotetext{
21 Conforme noticiado pelo site G1, em 08/06/2020. Acesso em 15 de agosto de 2021. Disponível em https://g1.globo.com/politica/noticia/2020/06/08/veiculos-de-comunicacao-formam-parceria-para-dar-transparencia-a-dados-decovid-19.ghtml.
} 
respondentes durante o período da pandemia ${ }^{22}$, foi responsável pela percepção ampliada de que o volume de trabalho aumentou muito.

O vetor temporal também está no cerne da intensificação do trabalho, com a sensação de que se está trabalhando mais na jornada regular de trabalho ou de que essa jornada se expandiu em razão das dificuldades de manejo das atividades partilhadas (do lar, de cuidados etc.) ou das adversidades provenientes da inadequação dos meios de trabalho disponíveis no espaço doméstico. Diante disso, muitos trabalhadores relataram sentir que estavam trabalhando 24 horas por dia, sentimento este exacerbado sobretudo pela conexão contínua, possibilitada pelas tecnologias digitais, as quais, ao serem usadas como meios de trabalho, aprisionam os trabalhadores em uma condição de presentificação e disponibilidade absoluta, simbolizada pela expressão "on" em seus status nas plataformas e aplicativos (Fígaro, 2021:74).

A pressão exercida pelo aumento (real ou sentido) de trabalho gera o desencadeamento de mecanismos desacelerativos, ou inércia acelerativa, em particular vinculados ao adoecimento físico e às limitações decorrentes do esgotamento cognitivo. Este quadro é completado pelo fato de que o Brasil é o país que mais registrou mortes de jornalistas vítimas de Covid-19 até o momento. Segundo a Federação Nacional de Jornalistas (FENAJ), até de 10 de agosto de $2021^{23}$ um total de 278 jornalistas perderam a vida por conta da doença. Apenas nos três primeiros meses de 2021 foram 199 mortes, mais do que em todo o ano de 2020. Ainda que estes trabalhadores estivessem listados como atividade essencial, até meados de 2021 a maioria dos estados brasileiros não havia incluído os jornalistas entre os profissionais com direito de acesso à vacina.

Muitas reflexões ainda poderiam ser apontadas. Certamente, nos próximos anos novos estudos nos permitirão reconhecer particularidades destas situações de afetação entre pandemia e Tempo Social. Não pretendemos dar conta da totalidade das circunstâncias que rodeiam este tema. Ao contrário, buscamos algumas referências que nos permitam observar processos sociotemporais de aceleração e desaceleração do Tempo Social em um campo particular, o do Jornalismo. Mas consideramos relevante, antes de encerrar esta reflexão, apontarmos alguns indícios que poderiam nos conduzir para uma observação acerca da terceira categoria de aceleração proposta por Rosa (2019), denominada aceleração da mudança social. Esta categoria diz respeito ao aumento de taxas de “[...] expiração de experiências e expectativas orientadoras da ação, e como encurtamento dos intervalos de tempo que, para cada esfera funcional, de valor de ação, pode ser determinado como presente" (Rosa, 2019:152). Rosa (2019) enfatiza que existe um amplo sentimento de insegurança em relação ao futuro na Modernidade Tardia, que desemboca numa sensação de pressão temporal sobre um futuro desconhecido e num medo de

\footnotetext{
${ }^{22}$ Outros $20 \%$ dos respondentes afirmaram trabalhar em modalidade híbrida, com parte da carga horária em home office e parte na organização empregadora. Apenas $11 \%$ dos entrevistados afirmaram estar atuando apenas na modalidade presencial (Fígaro, 2021:63).

${ }^{23}$ Disponível em https://fenaj.org.br/278-jornalistas-mortos-pela-covid-19-no-pais/. Acesso em 15 ago. 2021.
} 
ser tornar anacrônico. Associamos a essa categoria uma categoria de inércia acelerativa, reconhecida por Rosa (2019) em fenômenos de "enrijecimento cultural". Tais fenômenos se baseiam na forte suspeita de que as rápidas mudanças que atingem a Modernidade Tardia, na realidade, seriam superficiais, visto que as estruturas sociais se tornariam cada vez mais rígidas e imutáveis (Rosa, 2019).

Uma das possibilidade de pensar sobre este processo, em particular no contexto do Jornalismo, é através de considerações sobre o papel da desinformação nos processos de comunicação no contemporâneo. Um dos desafios históricos do Jornalismo (mas não apenas dele), a desinformação também foi agente relevante no contexto da pandemia. Segundo o relatório Reuters Institute Digital News Report 2021,

\begin{abstract}
As preocupações globais sobre informação falsa e enganosa aumentaram ligeiramente este ano, variando de $82 \%$ no Brasil a apenas $37 \%$ na Alemanha. Aqueles que utilizam os meios de comunicação social são mais propensos a dizer que foram expostos a desinformação sobre o Coronavírus do que os não utilizadores. O Facebook é visto como o principal canal de divulgação de informação falsa em quase todo o lado, mas aplicações de mensagens como a WhatsApp são vistas como um problema maior em partes do Sul Global, como o Brasil e a Indonésia.
\end{abstract}

O registro de que o Brasil é o país com mais alto índice de preocupação sobre informações falsas ou enganosas (atingindo a marca de $82 \%$ entre os respondentes da pesquisa global desenvolvida pelo Reuters Institute), colabora para reforçar a compreensão de que a desinformação tem operado de modo decisivo em nosso cenário pandêmico, de modo que, segundo Fígaro (2021:79), "o combate à disseminação de desinformação e/ou fake news por meio de um trabalho de comunicação e jornalismo "correto", da "verdade", foi assumido como uma atividade essencial, em especial no contexto da pandemia”. A pandemia de forma alguma inaugura este processo, mas de modo relevante parece estar impelindo o Jornalismo a se reposicionar na relação com sua audiência.

\title{
Considerações finais
}

Se a pandemia forçou um intenso processo de desaceleração social globalizado, não é correto afirmar que este tenha de dado de forma homogênea. Ao contrário, como buscamos salientar, o Tempo Social tem como característica central a heterogeneidade, articulada a partir de múltiplas temporalidades. Mesmo em um campo particular, diferentes variáveis podem ser consideradas para apontarmos processos simultâneos de aceleração e desaceleração. Nos parece claro, entretanto, como destaca Rosa (2020) que a digitalização acentuada da vida contemporânea reflete de forma sustentada um processo de aceleração técnica com efeitos 
concretos nas relações sociais e nos ritmos da vida. Enquanto diferentes esferas da vida inesperadamente foram deslocadas de suas lógicas rotineiras (transportes, circulação urbana etc.), parte consistente do cotidiano pode manter suas dinâmicas internas e, até mesmo, tiveram seus processos ampliados e acelerados.

A reflexão de Rosa (2020) merece, entretanto, algumas pontuações sobre as quais o caso brasileiro parece exemplar. Rosa defende, de forma enfática, que uma das características singulares do processo de desaceleração forçada [Zwangsentschleunigung] foi reconhecido no papel atuante dos governos como mediadores da crise sanitária e orientadores das decisões coletivas, frente à diferentes reguladores sociais, como o mercado, por exemplo. É certo que em grande parte dos países esse cenário pode ser acompanhado. Certo também que existem exceções relevantes, que podem oferecer um campo profícuo para análises mais dedicadas ao tema das sociotemporalidades, em particular sobre seus limitadores e dinamizadores. Algumas pesquisas recentes têm apontado para o papel significativo do Jornalismo na construção de orientações frente a contextos de franca desorientação, como o que a pandemia gerou. Na China, por exemplo, os pesquisadores reconheceram que "[...] um elevado grau de atenção e dependência dos meios de comunicação social pode desencadear uma maior auto-eficácia percebida" (Gongo et al., 2021:14), colaborando para ações individuais orientadas à busca de bem-estar e de comportamentos de ajuda.

A pandemia de Covid-19, como acontecimento-limite que marca um momento histórico singular, certamente continuará a operar como recorte temporal para investigações em diferentes campos do conhecimento, entre eles a Sociologia. Muito há que se compreender sobre este momento e, em particular, sobre os desdobramentos que as experiências (individuais e coletivas) deste período acarretarão no futuro próximo. Nosso objetivo com este texto foi o de pontuar uma perspectiva particular, a dos reflexos sociotemporais da pandemia no contexto social, em particular no Jornalismo. As escolhas indicadas para representar esse processo certamente não esgotam as oportunidades de observação deste fenômeno. Ao contrário, nos parecem apenas indicar direcionamentos indiciais que precisam ser explorados em profundidade.

\section{Referências}

ADAM, Barbara (1990), Time and Social Theory. Cambridge, Polity Press.

BÉDARIDA, François (2002), "Tempo presente e presença da história” in M. M Ferreira e J. Amado (Orgs.), Usos e abusos da história oral. 5.ed. Rio de Janeiro, Ed. FGV, 2002.

BENETTI, Marcia (2013), "Revista e jornalismo: conceitos e particularidades", in F. Tavares e R. Schwaab (Orgs.), A revista e seu jornalismo. Porto Alegre, Penso, pp. 44-57. 
CHARAUDEAU, Patrick (2007), O discurso das mídias. São Paulo, Contexto.

CHAUVEAU, Agnès; TÉTART, Philippe (1999), Questões para a História do Presente. Bauru, EDUSC.

COMTE, Auguste (1983), "Curso de Filosofia Positiva”, in Os Pensadores. São Paulo, Abril Cultural, pp. $1-41$.

COMTE-SPONVILLE, André (2000), O Ser-Tempo. São Paulo, Editora Martins Fontes.

DALMONTE, Edson Fernando (2010), "Presente: o tempo do jornalismo e seus desdobramentos". Revista História, v. 29, n. 01, pp.328-344 [Consult. 10-08-2021]. Disponível em https://doi.org/10.1590/S0101-90742010000100019

DURKHEIM, Émile (1996), As formas elementares da vida religiosa: o sistema totêmico na Austrália. São Paulo, Martins Fontes.

DURKHEIM, Émile (2010), Da divisão do trabalho social. $4^{\text {a }}$ Ed. São Paulo, Martins Fontes.

ELIAS, Norbert (1998), Sobre o Tempo. Rio de Janeiro, Editora Zahar.

FIGARO, Roseli (2021), Como trabalham os comunicadores no contexto de um ano da pandemia de Covid-19. São Paulo, ECA-USP: Centro de Pesquisa em Comunicação e Trabalho.

FRANCISCATO, Carlos Eduardo (2005), A fabricação do presente: como o jornalismo reformulou a experiência do tempo nas sociedades ocidentais. São Cristóvão, Editora UFS.

GONG, Jiankun; ZANUDDIN, Hasmah; HOU, Weipeng; XU, Jinghong (2021), "Media attention, dependency, selfefficacy, and prosocial behaviours during the outbreak of COVID-19: A constructive journalism perspective". Global Media and China, v. XX, pp. 1-18 [Consult. 10-08-2021]. Disponível em https://doi.org/10.1177/20594364211021331

GRONMO, Sigmund (1989), “Concepts of Time: Some Implications For Consumer Research". In: SRULL, Thomas (Org.). Advances in Consumer Research. v. 16. Utahv Provo, pp. 339-345.

GROS, Alexis; TORRES, Felipe (2020), “¿Desaceleración de la aceleración? Descripción y normatividad de la velocidad social en tiempos de pandemia". Teoría \& Cambio Social-CLACSO, n. 03, pp. 60-70.

GUEDES, Eduardo Rosa (2020), “A Sociedade Moderna e suas múltiplas dimensões temporais: um breve mapeamento do Tempo Social nas teorias sociológicas de 1930-1970”, in Simpósio Internacional Desigualdades, Direitos e Políticas Públicas. Anais Eletrônicos... São Leopoldo, Editora Casa Leiria, 2020. pp. 3707-3721 [Consult. 12-08-2021].

Disponível em http://www.guaritadigital.com.br/casaleiria/acervo/cienciassociais/viisiddpp/index.html

GUEDES, Eduardo Rosa; STORCH, Laura Strelow (2020), "O tempo na modernidade e a estabilização dinâmica das estruturas sociais". Comtemporânea - Revista de Sociologia da UFSCar, v. 10, n. 02, pp. 825-833.

GUEDES, Eduardo Rosa (2021), "Perspectivas da Internet: um ensaio comparativo entre Pierre Levy e Paul Virilio". Novos Rumos Sociológicos - NORUS, v. 9, n. 15, pp. 256-272 [Consult. 12-08-2021] Disponível em https://periodicos.ufpel.edu.br/ojs2/index.php/NORUS/article/view/20839/13470

GURVITCH, Georges (1987), Dialética e Sociologia. São Paulo, Editora Vértice, 1987.

GURVITCH, Georges (1964), The spectrum of Social Time. Dordrecht, D. Reidel Publishing Co. 
KOSELLECK, Reinhardt (2006), Futuro passado: contribuição à semântica dos tempos históricos. Rio de Janeiro, Editora Contraponto.

LACCOUTURE, Jean (2001), “A História imediata”, in J. Le Goff, A história nova. São Paulo, Martins Fontes, 2001, pp. 216-236.

LACERDA, Marcos (2020), A Sociedade das Tecnociências de Mercadorias. Rio de Janeiro, Ateliê de Humanidades.

LECCARDI, Carmen (2014), Sociologías del Tiempo. Chile, Silu-Chile.

LE GOFF, Jacques (2012), História e Memória. 6ª ed. Campinas, Editora Unicamp, 2012.

LÜBBE, Herman (2009), “The contraction of the presente”, in H. Rosa, W. Scheuerman (Orgs), Highspeed society: social acceleration, power and modernity. Philadelphia, Pennsylvania University Press, pp. 159-179.

MARTINS, Hermínio (2011), Experimentum Humanum: civilização tecnológica e condição humana. Lisboa, Relógio D’água.

MEAD, George Herbert (1932), The Philosophy of the Present. United States, Prometheus Books.

MONTEIRO, José Fernando Saroba (2018), "Tempo presente: entre os métiers do historiador e do jornalista". Revista Tempo e Argumento, v. 10, n. 24, pp. 510-539 [Consult. 20-08-2021]. Disponível em https://doi.org/10.5965/2175180310242018510

NEWMAN, Nic; FLETCHER, Richard; SCHULZ, Anne; ANDI, Simge; ROBERTSON, Craig; NIELSEN, Rasmus K (2021), Reuters Institute Digital News Report. $10^{\mathrm{a}}$ Ed. Oxford, Reuters Institute.

REGINATO, Gisele (2018), “As finalidades do jornalismo: percepções de veículos, jornalistas e leitores”. Revista Famecos, v. 25, n. 3, pp. 01-18 [Consult. 20-08-2021]. Disponível em https://doi.org/10.15448/1980-3729.2018.3.29349

RONCALLI, Angelo; LACERDA, Juciano de Souza (2020), "Jornalismo como forma de conhecimento: a questão da divergência dos dados de tendência da covid-19 divulgados pelo consórcio de imprensa e pela SESAP-RN". Scielo PrePrints [Consult. 25-08-2021]. Disponível em https://doi.org/10.1590/SciELOPreprints.1141

ROSA, Hartmut (2017), "Modernidade dessincronizada: aceleração social, destemporalização e alienação: uma entrevista com Hartmut Rosa”. Estudos de Sociologia, v. 22. n. 43, pp. 365-383.

ROSA, Hartmut (2019), Aceleração: a transformação das estruturas temporais na Modernidade. São Paulo, UNESP.

ROSA, Hartmut (2021), "La Sociedad ante la desaceleración forzada: una interpretación sociológica de la crisis del coronavirus". Diferencia(s) Revista de Teoría Social Contemporánea, v. 11, n. 11, pp. 19-32.

SADRI, Sean R.; BUZELLI, Nicholas R.; GENTILE, Patrick; BILLINGS, Andrew C. (2021), "Sports journalism content when no sports occur: framing athletics amidst the Covid-19 international pandemic". Communication \& Sports, XX(X), pp. 1-24 [Consult. 18-09-2021]. Disponível em https://doi.org/10.1177/21674795211001937

SELL, Carlos Eduardo (2013), Max Weber e a Racionalização da Vida. Petrópolis, Editora Vozes.

SILVA, Gislene; SILVA, Marcos Paulo da; FERNANDES, Mario Luiz (2014), Critérios de Noticiabilidade: problemas conceituais e aplicações. Florianópolis, Insular. 
SIMMEL, Georg (1998), "A divisão do trabalho como causa da diferenciação da cultura subjetiva e objetiva” in J Souza, B. Öelze (Orgs.), Simmel e a modernidade. Brasília, Editora UnB, pp. 41-77.

SIMMEL, Georg (2005), “As grandes cidades e a vida do espírito”. Mana, v. 11, n. 2, p. 577-59.

SOROKIN, Pitirim (1970), "O Tempo Sociocultural: características preliminaries do Tempo Sociocultural" in F. H. Cardoso e O. Ianni, Homem e Sociedade. São Paulo, Editora Nacional, pp. 231236.

STORCH, Laura (2012), O leitor imaginado no jornalismo de revista: uma proposta metodológica. [Tese Doutorado] PPG em Comunicação e Informação. Porto Alegre, UFRGS. 174 p.

SZTOMPKA, Piotr (2005), A sociologia da Mudança Social. Rio de Janeiro, Civilização Brasileira.

TZIMINADIS, João Lucas Faco (2018), Frenesi em suspensão: em direção a um modelo crítico a partir da teoria da aceleração social de Hartmut Rosa. 2018. Dissertação (Mestrado em Ciências Sociais) Faculdade de Ciências e Letras, Universidade Estadual Paulista Júlio de Mesquita Filho, São Paulo. $136 \mathrm{p}$.

VIANA, Diego (2019), "Velozes e furiosos: filósofo alemão estuda cinco séculos de aceleração técnica, social e do ritmo da vida". Folha de São Paulo, São Paulo, 07 de abr. [Consult. 24-11-2020]. Disponível em Quatro Cinco Um: a revista dos livros - Velozes e furiosos

VIRILIO, Paul (1993), A inércia polar. Lisboa, Dom Quixote.

VIRILIO, Paul (1999), A bomba informática. São Paulo, Estação Liberdade.

WAJCMAN, Judy (2017), Esclavos del tiempo: vidas aceleradas en la era del capitalismo digital. Buenos Aires, Editora Paidos.

WEBER, Max (2004), A ética protestante e o "espirito" do capitalismo. São Paulo, Companhia das letras.

WEBER, Max (2015), Ciência e Política: duas vocações. São Paulo, Editora Cultrix.

WHITEHEAD, Alfred (1978), Process and Reality: an essay in Cosmology. New York, The Free Press. 


\begin{abstract}
The Covid-19 pandemic has extensively changed social relations and socio-temporal perceptions, including those in the specific field of Journalism. The article departs from a theoretical debate about Social Time to discuss the accelerative and desacelerative reflexes of the pandemic in social routines and practices associated with the production and circulation of journalistic content. We consider the theoretical perspective of acceleration proposed by the German sociologist Hartmut Rosa, in particular categories such as technical acceleration, acceleration of the rhythms of life and acceleration of social change, in order to contribute to the consolidation of sociological readings on time and social relations.
\end{abstract}

Keywords: social time; acceleration; sociology; journalism; pandemic; Covid-19.

\title{
Resumen
}

La pandemia de Covid-19 ha cambiado enormemente las relaciones sociales y las percepciones sociotemporales, incluidas las del campo específico del periodismo. El artículo parte de un debate teórico sobre el Tiempo Social para discutir los reflejos acelerativos y desacelerativos de la pandemia en las rutinas y prácticas sociales asociadas a la producción y circulación de contenidos periodísticos. Consideramos la perspectiva teórica de la aceleración propuesta por el sociólogo alemán Hartmut Rosa, en categorías particulares como aceleración técnica, aceleración de los ritmos de vida y aceleración del cambio social, con el fin de contribuir a la consolidación de lecturas sociológicas sobre el tiempo y las relaciones sociales.

Palabras-clave: tiempo social; aceleración; sociología; periodismo; pandemia; Covid-19. 